\title{
Characterization of the invariable residue 5 I mutations of human immunodeficiency virus type I capsid protein on in vitro CA assembly and infectivity
}

\author{
Samir Abdurahman ${ }^{\dagger 1}$, Masoud Youssefi ${ }^{\dagger 1}$, Stefan Höglund ${ }^{2}$ and
} Anders Vahlne*1 \author{
of Biochemistry, Uppsala University, Uppsala, Sweden \\ Email: Samir Abdurahman - Samir.Abdurahman@ki.se; Masoud Youssefi - Masoud.Youssefi@ki.se; \\ Stefan Höglund - Stefan.hoglund@biorg.uu.se; Anders Vahlne* - Anders.Vahlne@ki.se \\ * Corresponding author †Equal contributors
}

Address: ${ }^{1}$ Division of Clinical Virology, Karolinska Institutet, F68 Karolinska University Hospital, SE-141 86 Stockholm, Sweden and ${ }^{2}$ Department

Published: 28 September 2007

Retrovirology 2007, 4:69 doi:10.1186/1742-4690-4-69

This article is available from: http://www.retrovirology.com/content/4/1/69

(C) 2007 Abdurahman et al; licensee BioMed Central Ltd.

This is an Open Access article distributed under the terms of the Creative Commons Attribution License (http://creativecommons.org/licenses/by/2.0), which permits unrestricted use, distribution, and reproduction in any medium, provided the original work is properly cited.

\begin{abstract}
Background: The mature HIV-I conical core formation proceeds through highly regulated protease cleavage of the Gag precursor, which ultimately leads to substantial rearrangements of the capsid (CAp24) molecule involving both inter- and intra-molecular contacts of the CAp24 molecules. In this aspect, Asp5I which is located in the N-terminal domain of HIV-I CAp24 plays an important role by forming a salt-bridge with the free imino terminus Prol following proteolytic cleavage and liberation of the CAp24 protein from the Pr55Gag precursor. Thus, previous substitution mutation of Asp5I to alanine (D5IA) has shown to be lethal and that this invariable residue was found essential for tube formation in vitro, virus replication and virus capsid formation.
\end{abstract}

Results: We extended the above investigation by introducing three different D5I substitution mutations (D5IN, D5IE, and D5IQ) into both prokaryotic and eukaryotic expression systems and studied their effects on in vitro capsid assembly and virus infectivity. Two substitution mutations (D5IE and D5IN) had no substantial effect on in vitro capsid assembly, yet they impaired viral infectivity and particle production. In contrast, the D5IQ mutant was defective both for in vitro capsid assembly and for virus replication in cell culture.

Conclusion: These results show that substitutions of D5I with glutamate, glutamine, or asparagine, three amino acid residues that are structurally related to aspartate, could partially rescue both in vitro capsid assembly and intra-cellular CAp24 production but not replication of the virus in cultured cells.

\section{Background}

The HIV-1 Pr55Gag precursor, which comprises the inner structural proteins of the virus, is sufficient for assembly of retrovirus-like particles in mammalian cells. During HIV1 assembly and maturation, the transformation of the virus from a spherical to a conical core structure results as a consequence of substantial inter- and intra-molecular rearrangements of one of the Pr55Gag derived proteins, namely the capsid protein (CAp24). This process is initially driven by the viral protease which sequentially 
cleaves Pr55Gag and liberates the mature structural proteins that forms the viral core structure $[1,2]$. The mature conical HIV-1 core, which is composed of approximately 1500 CAp24 molecules [3], is comprised of two independently folded subunits, the $\mathrm{N}$ - and C-terminal domains (NTD and CTD) [4]. The N-terminal domains of CAp24 are assembled into hexameric rings [5] and each hexameric ring is joined to the neighbouring ring by the CTDs of CAp24 resulting in a lattice with local p6 symmetry.

The availability of high resolution structures combined with mutagenesis studies of the HIV-1 CAp24 have provided important insights on the structure and mechanisms of virus assembly. Using these biological techniques, the importance of Asp51 in the NTD of CAp24 has been described before [6]. The study showed that mutation of Asp51 to alanine to be lethal. Thus, this invariable residue was shown to be essential for CAp24 tube formation in vitro, and for HIV-1 replication and capsid formation in cultured virus [6]. During proteolysis of the Pr55Gag and maturation of CAp24, the NTD of CAp24 refolds into a $\beta$-hairpin structure which is then stabilized by formation of a salt-bridge between Pro1 and Asp51 of the processed NTD (Fig. 1). The fact that this structure is not formed in immature virus-like structures [7] also indicates that this motif does not form in an immature particle. The importance of this structure is further emphasized by the fact that all mature retroviral capsids, with possible exception of foamy virus, contain an $\mathrm{N}$ terminal $\beta$-hairpin loop. In the case of murine leukemia virus for example, a virus which belongs to a gamma-retrovirus family, Pro1 forms a salt-bridge with a highly conserved Asp54, which is the equivalent to Asp51 in HIV [8]. A high degree of conservation among residues involved in formation and stabilization of this structure also exists in various retroviruses. In multiple sequence alignment analysis of 4198 HIV-1 CAp24 sequences found in the HIV database (May 7, 2007), we found only 11 exceptions to the highly conserved Asp51 among all HIV-1 strains, demonstrating that this residue is not only conserved among various retroviruses but also in HIV strains.

Since mutation of Asp51 to alanine has shown to be critical for proper capsid formation and subsequent replication of the virus, we extended the above findings and examined amino acid substitutions of this invariable residue to asparagine, glutamate, and glutamine. All three amino acid residues closely resemble aspartate and were anticipated not to grossly interrupt the CAp24 structure. We designed the mutated Cap24 sequences in both prokaryotic and eukaryotic expression systems and studied their effects in vitro, as well as, in vivo. Two of the three mutants (D51E and D51N) were stable in vitro as was evidenced by forming highly polymerized capsid

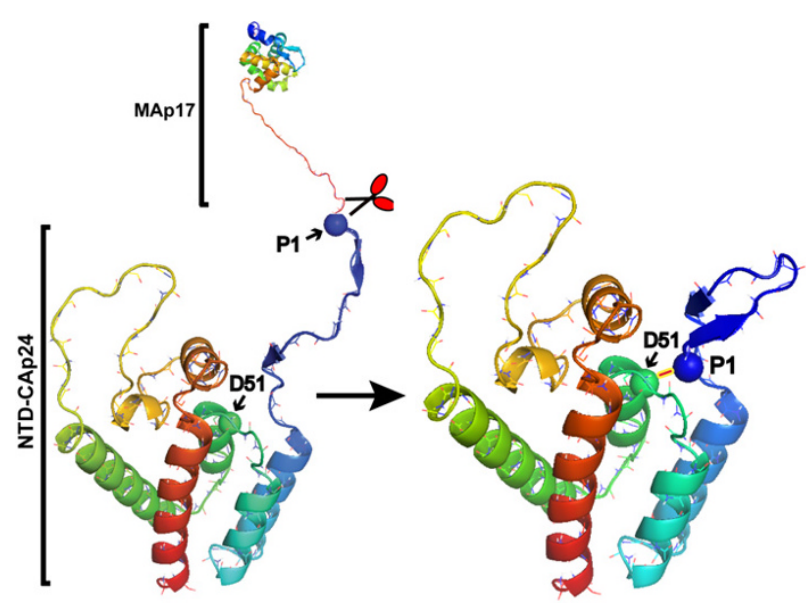

Figure I

Ribbon representation showing the MApI7 and the $\mathrm{N}$-terminal CAp24 domain of the unprocessed Pr55Gag. Ribbon diagram of the MAp17 [33] and CAp24 [34] depicting the structural rearrangemts that takes place in the N-terminal domain (NTD) of CAp24 upon proteolytic processing at the MAp 17-CAp24 junction (indicated with a sax). The model to the right represents a processed NTD CAp24 showing the $\beta$-hairpin formation which is stabilized by the salt-bridge formation between the imino terminal Pro I and Asp 5I. For clarity, Por I and Asp 5I are shown as filled circles. The ribbon diagrams were generated with the PyMOL [35] and modified with Adobe Photoshop software.

tubular structures that were closely resembling wild type structure, however, the infectivity and in vivo morphological structures of all three mutants were severely affected.

\section{Results \\ Viral protein expression of HIV-I CAp24 mutants}

We investigated the effects of three HIV-1 CAp24 mutants carrying the D51N, D51E, and D51Q mutations for viral protein expression by initially transfecting HeLa-tat cells. Total cell lysates were immunoblotted and detected with polyclonal antibodies directed against gp120/gp160 (Figure 2A), a pool of antibodies against CAp24 and calnexin (Figure $2 \mathrm{~B}$ ), and precipitated viral lysates were immunoblotted with a pool of HIV-positive sera from two individuals (Figure 2C). Two to three days post-transfection, processed HIV-1 Pr55Gag proteins were detected in all cell lysates. The relative intracellular level of the Pr55Gag precursor in all mutants was comparable to that of the wild type, whilst the D51N and D51Q mutants displayed somewhat reduced levels of the CAp24. Whereas the D51Q mutant displayed a slightly reduced amount of CAp24, the level of processed CAp24 proteins in the D51N mutant was significantly reduced relative to the wild type and the D51E CAp24 mutant. To further evaluate the level of viral proteins in released virions, normal- 


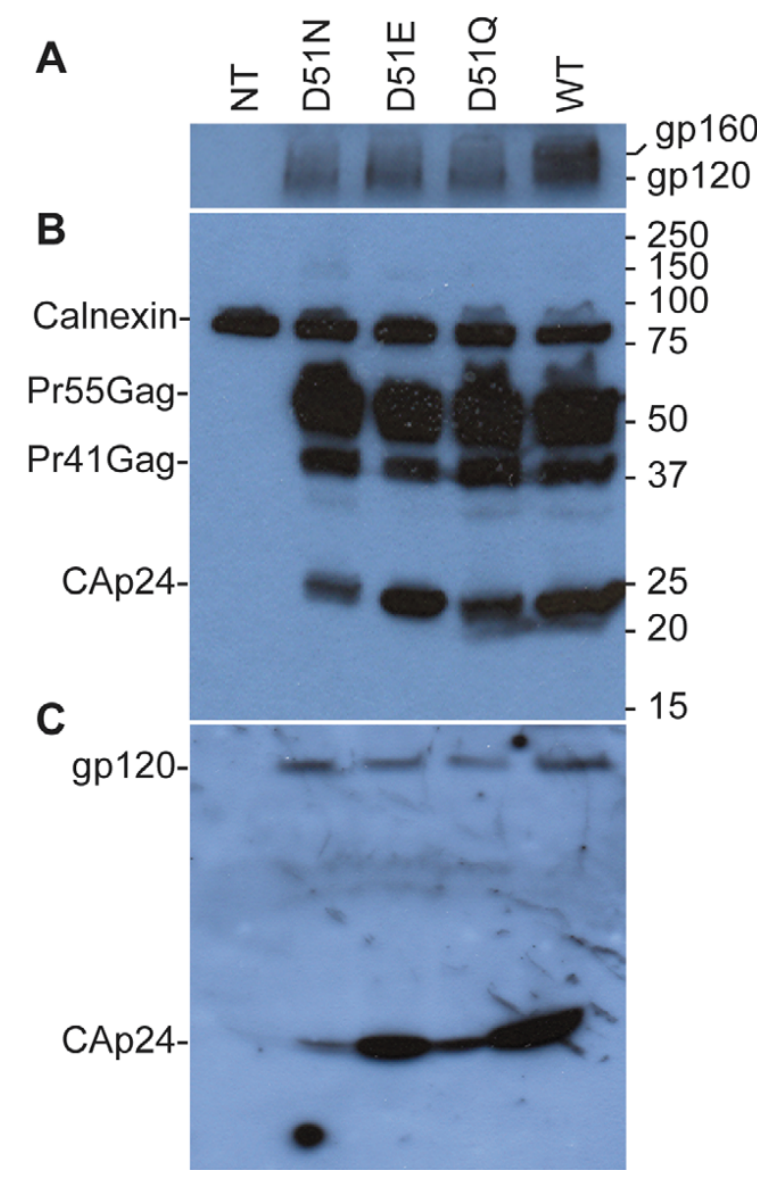

\section{Figure 2}

Western blot analysis of transfected HeLa-tat cell and precipitated viruses. HeLa-tat cells were transfected with the plasmids indicated using the non-liposomal transfection reagent. Forty-eight hrs post-transfection, cells were washed and harvested in I $\times$ RIPA buffer. Particles released into the culture supernatant were also clarified and filtered of cell debris and precipitated with Viraffinity (CPG) as recommended by the manufacturer. Denatured cell (A and $B)$ and viral lysates $(C)$ were then separated by SDS-PAGE, transferred onto a nitrocellulose membrane and detected with a rabbit anti-HIV glycoprotein (A), a pool of anti-CAp24 and anti-calnexin (B), and anti-CAp24 (C) antibodies. The positions of specific viral proteins are indicated to the left and the numbers to the right depict positions of molecular mass markers (in kDa). NT, a mock control; WT, wild type; and D5IN, D5IE, and D5IQ are the three CAp24 mutants.

ized amounts of culture supernatants were precipitated with Viraffinity and detected with immunoblotting using both monoclonal and polyclonal anti-CAp24 antibodies (data not shown) and a pool of HIV-positive sera from two individuals (Figure 2C). Mature CAp24 represented the major product of the precipitated material. However, the level of this protein in both D51N and D51Q mutants was significantly reduced relative to the wild type and D51E mutant, correlating with the lower intracellular CAp24 levels. A comparable level of the viral glycoprotein (gp120) incorporation into released virions was observed with all mutants and the wild type virus (Figure 2C). A similar result was also obtained with a V3 loop-specific monoclonal anti-glycoprotein antibody (data not shown).

The Pr55Gag expression and processing pattern was further characterized by transfecting HeLa-tat III, 293T and COS7 cells with the wild type and mutant pNL4-3 expression plasmids and detected with immunoblotting using a pool of HIV-positive human sera from two individuals (Figure 3). With HeLa-tat III cells (Figure 3), the levels of CAp24 detected with the D51N and D51Q were largely identical with those in HeLa-tat cells detected with a rabbit anti-CAp24 antibody (Figure 2B). Additionally, fully processed Pr55Gag proteins, as well as, the surface glycoproteins could be detected with all mutants when using a pool of HIV-positive human sera. Further reduction or absence of cell-associated CAp24 of the D51N and D51Q mutants was observed in both 293T and COS7 cells. Whereas no CAp24 was detected with the D51N mutant, significantly reduced level of this protein was observed with the D51Q mutant in both 293T and COS7 cells. Similar results were also obtained when using both monoclonal and polyclonal antibodies directed against CAp24 or the surface glycoprotein gp120/gp160, respectively (data not shown). With the wild type control, fully processed HIV-1 Gag proteins were detected in all three transfected cell lines. As an internal control, the level of cell associated cyclophilin A and calnexin were probed with polyclonal antibodies directed against these two proteins (Figure 3, lower panels).

\section{In vitro CAp24 assembly}

Turbidity assay is a valuable technique used to study a salt-induced self-assembly process of CAp24 by monitoring polymerization of CAp24 spectrophotometrically, as the rate of CAp24 tube formation can be seen as an increase in sample turbidity over time. One-hundred $\mu \mathrm{M}$ of each CAp24 was mixed with $\mathrm{NaH}_{2} \mathrm{PO}_{4}$ (pH 8.0) buffer and polymerization was induced by addition of concentrated $\mathrm{NaCl}$ solution. The rate of CAp24 tube formation was then measured spectrophotometrically (at $350 \mathrm{~nm}$ ) over time. As shown in Figure 4, an increase in sample turbidity was observed for both $\mathrm{D} 51 \mathrm{~N}$ and D51E mutant CAp24 proteins. However, as expected, the kinetics of CAp24 assembly was lower than that of the wild type control. In marked contrast, the rate of sample turbidity increase for the D51Q mutant CAp24 was higher than for the wild type control. This was quite surprising to us, as the increase in OD should be proportional to the total 


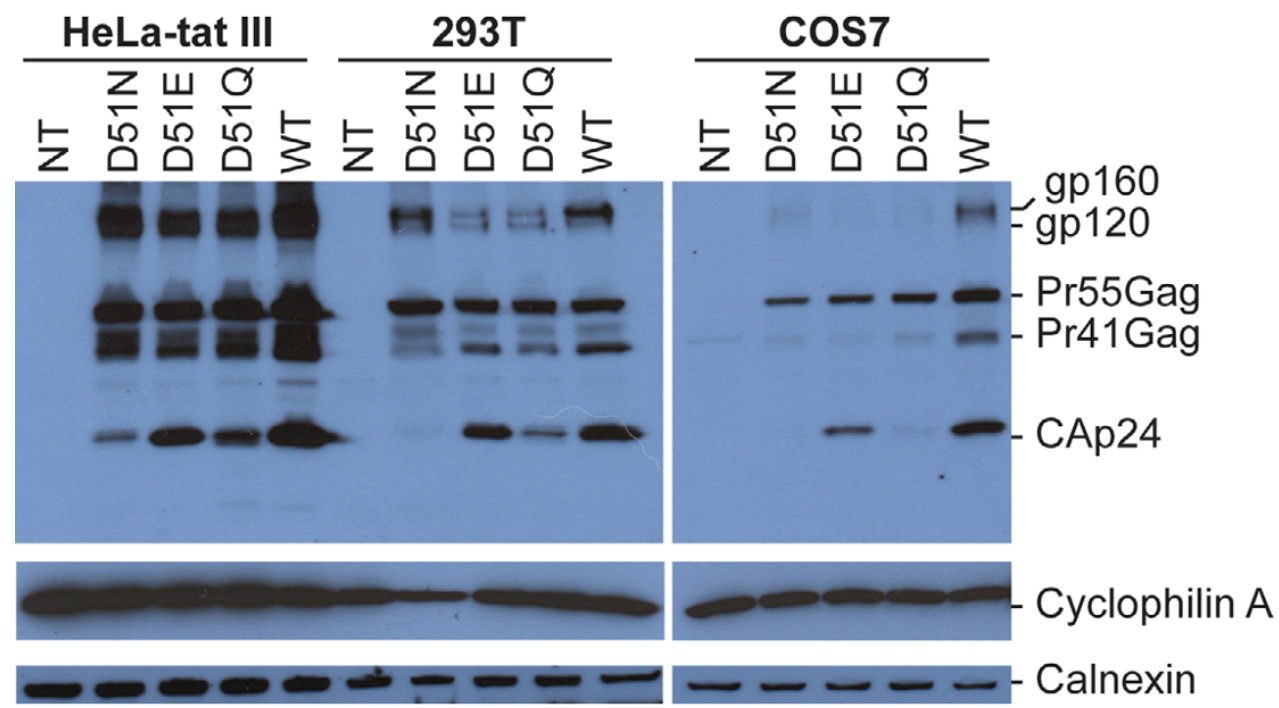

\section{Figure 3}

Western blot analysis of cell-type dependent expression of HIV-I proteins. HeLa-tat III, 293T and COS7 cells were transfected as described above with mutant and wild type proviral DNA constructs. Forty-eight hrs post-transfection, cells were washed and harvested in I $\times$ RIPA buffer. Denatured cell lysates were then resolved by SDS-PAGE, transferred to a nitrocellulose membrane and immunoblotted with a pool of two HIV-I positive sera (A), rabbit anti-cyclophilin A (B), and anti-calnexin (C) antibodies. Positions of specific viral and cellular proteins are indicated on the right.

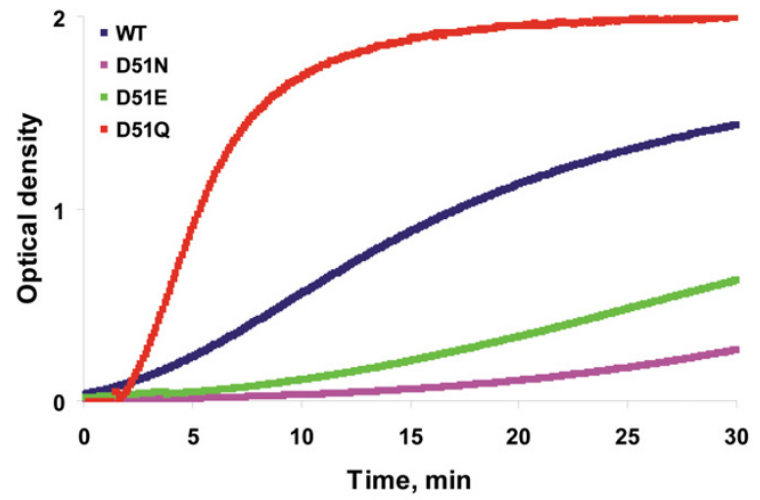

Figure 4

Turbidity assay showing the effects of CAp24 mutations on in vitro CA assembly. Turbidity assay showing the increase in light absorbance after addition of $2.0 \mathrm{M} \mathrm{NaCl}$ to recombinantly produced mutant and wild type CAp24 protein $(100 \mu \mathrm{M})$ reflecting the assembly of the CAp24 protein into tubular structures. Green, D5IE; red, D5 IQ; blue, wild type; pink, D5IN. The structures of polymerized CAp24 structures were also analyzed by transmission electron microscopy (Figure 5). number of CAp24 proteins assembled into tubular structures [9].

\section{Morphological analysis of structures formed by recombinant HIV CAp24 in vitro}

To determine the effects of CAp24 mutations on in vitro capsid assembly, thin-sections of the polymerized material used in turbidity assay was prepared and analyzed by transmission electron microscopy. As shown in Figure 5, long tubular structures were observed in both D51N and D51E mutant CAp24 proteins induced by addition of 2.0 $\mathrm{M} \mathrm{NaCl}$ solution. Additionally, the morphology of the tubes formed by these two was comparable to the structures formed by wild type CAp24, both in terms of external diameter and length of the tubes. In contrast, no structure that resembled CAp24 tubular formation was observed with the D51Q mutant CAp24 protein under the same conditions.

\section{Analysis of virus release and infectivity}

The effects of CAp24 mutations on Pr55Gag assembly and virus particle release was also analyzed by measuring the CAp24 antigen contents released into the culture medium of transfected HeLa-tat III, 293T and COS7 cells. As shown in Figure 6A, the CAp24 antigen levels in the culture supernatant of D51N and D51Q transfected cells were negligible in all three cell lines, whereas the virus produc- 

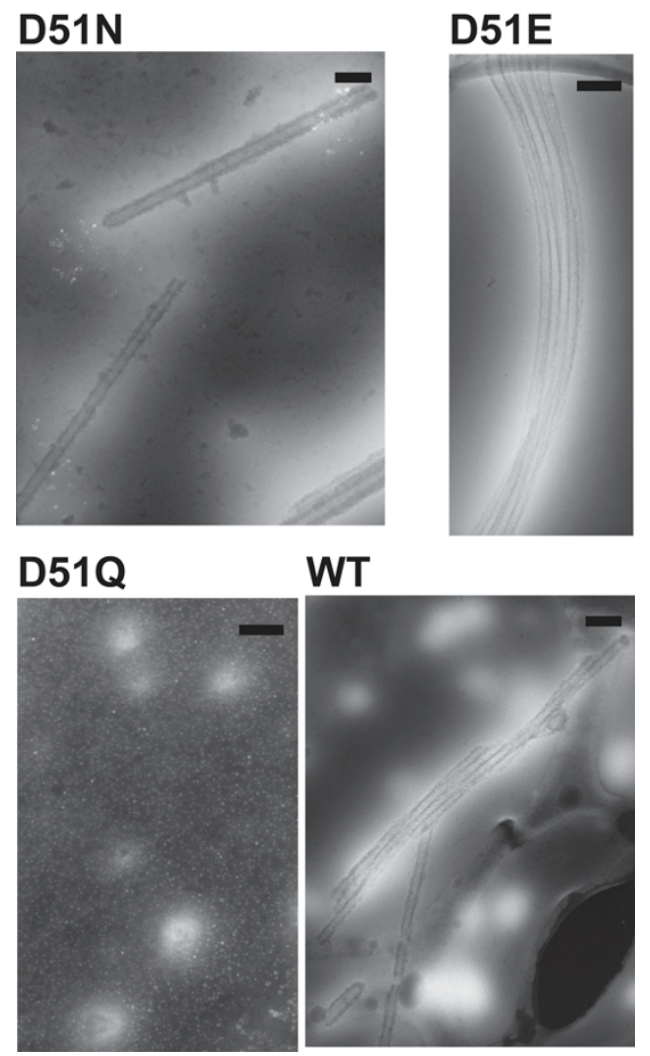

WT

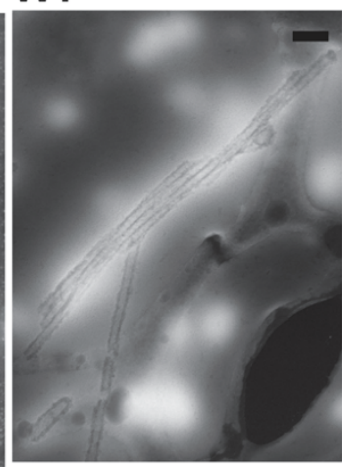

\section{Figure 5}

Morphological analysis of in vitro assembled mutant CAp24 proteins. Mutant and wild type CAp24 proteins were induced for in vitro CAp24 tubular formation (see Fig. 3). At the end of the experiment, the proteins were fixed in freshly prepared $2.5 \%$ glutaraldehyde. The electron micrographs show negatively stained thin-sections of the in vitro assembled CAp24 tubular structures used in turbidity assay. Micrographs of the CAp24 mutant D5IN (A), D5IE (B), D5IQ (C) and the wild type CAp24 (D). Bars indicate 100 $\mathrm{nm}$.

tion of the D51E mutant was reduced by 2- to 6-fold as compared to the wild type.

The effect of the three CAp24 mutations on virus infectivity was then assessed with culture supernatants from transfected HeLa-tat III, 293T and COS7 cells. MT4 cells were infected with equal amount of cleared and filtered culture supernatants (normalized for CAp24 antigen) and assayed for CAp24 antigen contents with a CAp24-ELISA three days post-infection (Figure 6B). While none of the three mutant viruses were able to replicate, as expected, the wild type virus replicated in this cell line. Similar results were also seen when the infectivity of mutant viruses was tested in $\mathrm{H} 9$ cells (data not shown). We kept the infected H9 cell cultures for more than 25 days without detecting virus replication with the mutants. No revertants to wild type virus were observed.

\section{Single cell cycle infectivity of HIV-I CAp24 mutant virions} Since the infectivity of all three CAp24 mutants were reduced or completely absent when assayed in MT4 cells, we analyzed the infectivity of these viruses produced from three different cell lines in a single cell cycle infectivity assay using the TZM-bl reporter cell line [10]. In this assay, expression of the reporter luciferase gene is under the con-

A Virus release

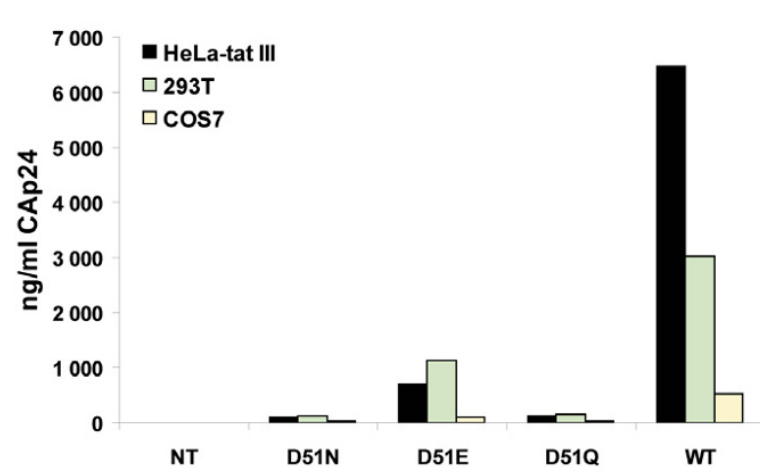

B
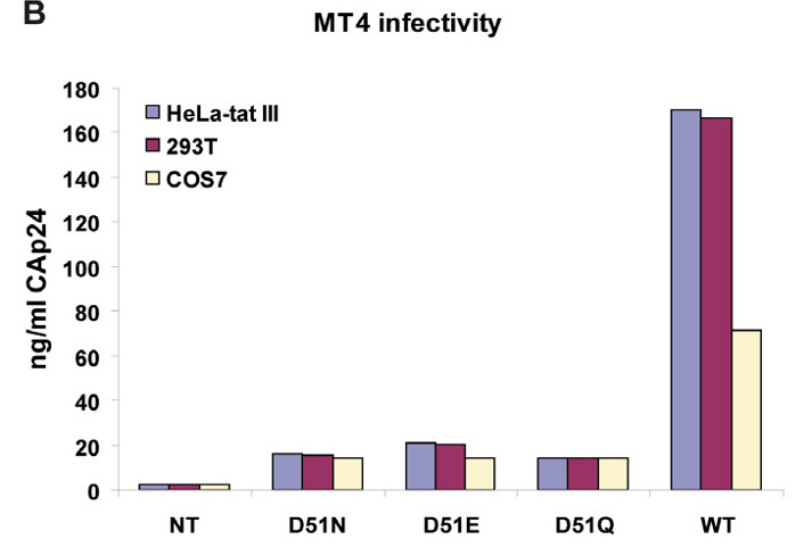

\section{Figure 6}

Virus release from transfected cells and their infectivity. HeLa-tat III, 293T, and COS7 cells were transfected with mutant and wild type proviral DNAs as indicated. (A) Three days post-transfection, culture supernatants were collected and analyzed by CAp24-ELISA. (B) Normalized amounts of cleared and filtered culture supernatants from the above transfected cells were then used to infect MT4 cells $\left(\mathrm{I} \times 10^{5}\right.$ cells per well in 48-well plate) using $100 \mathrm{ng}$ of CAp24 antigen. The bars indicate infectivity of the virus particles produced from the three different cell lines monitored by CAp24-ELISA. 
trol of Tat protein that is activated by Tat protein synthesized from the infecting virus. While the Tat-induced luciferase activity could not be detected in cells infected with mutant D51N and D51Q virions, only a subtle amount of luciferase activity was observed repeatedly in cells infected with the D51E virions (Figure 7). On the other hand, the level of Tat-induced luciferase activity was significantly higher in cells infected with the wild type virus.

\section{Immunofluorescence analysis of viral protein expression in transfected cells}

The viral protein expression profiles were further investigated by their staining patterns using monoclonal antibody directed against CAp24. All mutants displayed strong specific signals (indicated with arrows in Figure 8) concentrated near or at the plasma membrane. This feature was most pronounced in cells transfected with the three capsid mutants and not with the wild type pNL4-3 transfected cells. The staining pattern seen with the wild type control was mostly throughout the whole cytoplasm and the plasma membrane (Figure 8, panel WT). A representative staining pattern of each mutant and the wild type control is shown.

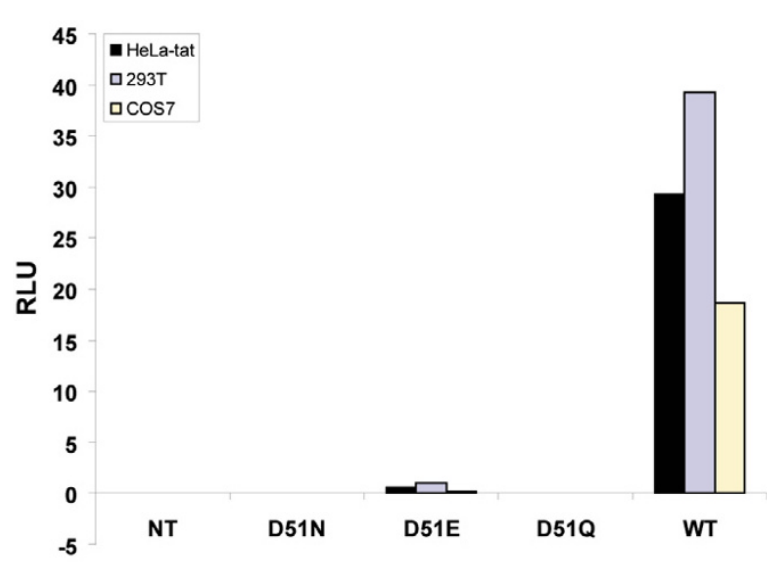

Figure 7

Single cell cycle infectivity of mutant and wild type virus particles on TZM-bl reporter cell lines. For relative viral infectivity assay, TZM-bl reporter cell lines were seeded one day before infection. Following day, medium was removed and target cells were inoculated by adding equal amounts of mutant and wild type NL4-3 virus produced from transfected HeLa-tat III, 293T, and COS7 cells. In this assay, expression of the reporter luciferase gene is under the control of Tat protein that is activated by Tat protein synthesized from the infecting virus. Infected cells were then analyzed $24 \mathrm{hrs}$ post-infection with the luciferase assay kit obtained from Promega and as recommended by the manufacturer. RLU, relative light unit.

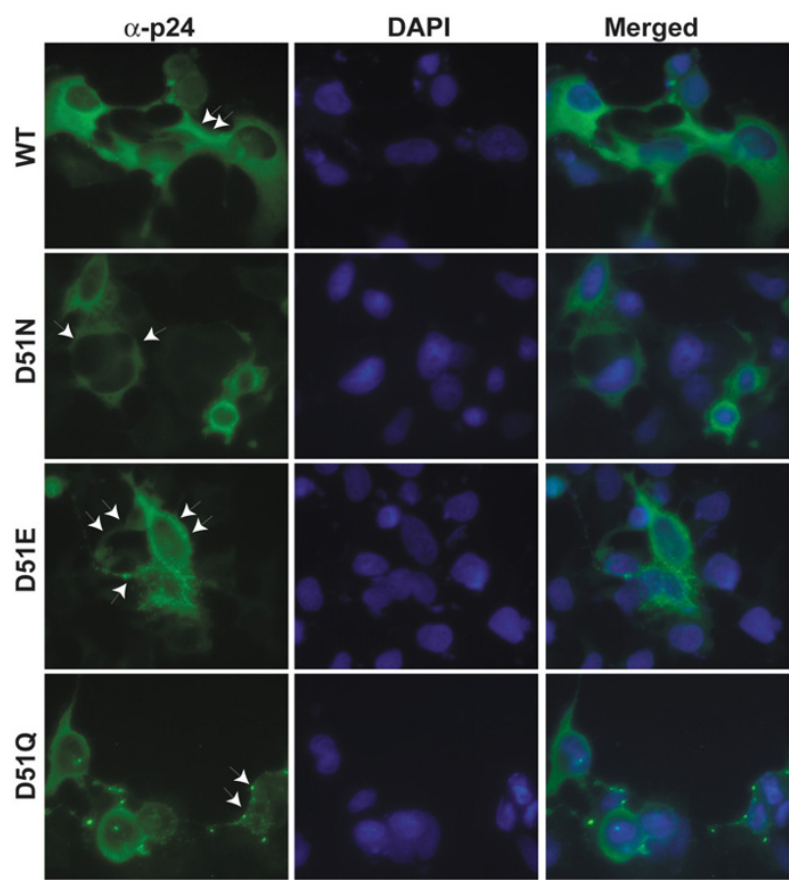

Figure 8

Immunofluorescence analysis of transfected HeLatat III cells. HeLa-tat III cells were transfected with mutant and wild type proviral DNA constructs. Forty-eight hrs posttransfection, cells were fixed and stained with a mouse antiCAp24 monoclonal antibody. As a secondary antibody, FITCconjugated (green) rabbit anti-mouse IgG was used. DAPI (4',6-diamidino-2-phenylindole dihydrochloride) was used to stain cell nuclei. The images in the right column represent an overlay of anti-CAp24 and DAPI stained images.

\section{Effect of HIV-I CAp24 mutations on virion morphology}

Morphogenesis of all mutant viruses and the wild type control were analyzed by transmission electron microscopy. The D51N and D51Q mutant virions showed mostly particles devoid of the typical HIV-1 core structure (Figure 9, panel D51N and D51Q). Instead, heterogeneous virus populations with aberrant core structures were observed. Additionally, the D51N virions showed a large pool of intra-vesicular viruses that were deficient of the electron dense core structure. Most strikingly, no mature virus particles with conical core structures were detected with these two mutants. A limited number of immaturelike viruses and occasionally mature-like viruses but with aberrant cores were observed with the D51E mutant. Only the wild type control produced viruses with typical immature- and mature-like HIV-1 virions (Figure 9, panel WT). Similar results were also observed when virus infected Jurkat-tat cells were analyzed (data not shown). 


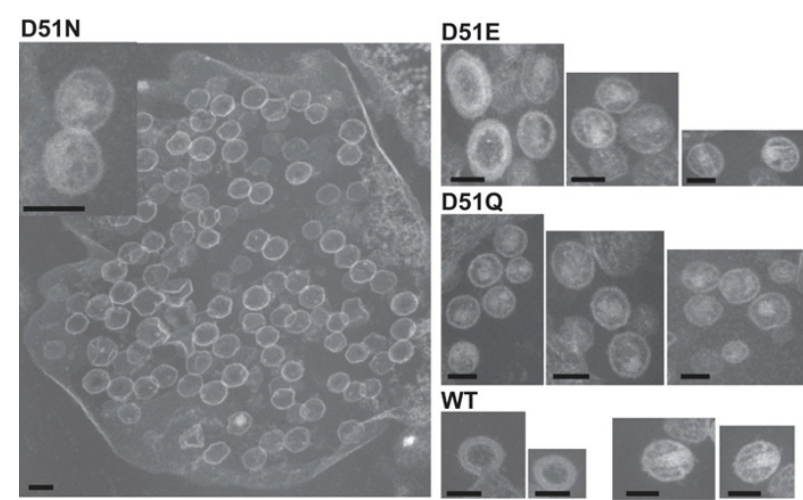

Figure 9

TEM analysis of mutant virus particles. Electron micrographs of mutant and wild type virus particles. Mutants D5IN and D5IQ showed mostly heterogenous populations of particles with varying size and morphology (panels D5IQ and inset in panel D5IN). No virus particles with conical core structures were observed with these two mutants. Additionally, a large pool of virus-like structures inside vesicles released from transfected cells were observed in D5IN mutant. With the wild type and D5IE virions particles representing immature-like viruses are shown (panels D5IE and WT). Mature viruses with conical structures were seen only in the wild type control virus. Occasionally, D5IE virions resembling the mature wild type morphology but with aberrant core structure was also observed. Bars indicate $100 \mathrm{~nm}$.

\section{Discussion}

Proper structural rearrangement of capsid (CAp24) after Pr55Gag cleavage is a highly conserved feature in most retroviruses [11]. As a result of this process, a $\beta$-hairpin structure formed by a salt-bridge between Pro1 and Asp51 (D51) of HIV-1 is important for conformational stability of the N-terminal CAp24 structure [6]. Thus, mutations of D51 in HIV-1 CAp24, and likewise Asp54 in murine leukemia virus (MLV) or human T-cell leukemia virus-1 (HTLV-1), has been shown to disrupt formation of this $\beta$ hairpin structure $[6,8,12]$.

Structural and mutagenesis studies of D51A mutation in HIV-1 CAp24 has previously shown this invariable residue to be essential for tube formation in vitro, and for the replication and capsid formation in cultured virus [6]. We here demonstrated that substitution of D51 with glutamate (D51E), asparagine (D51N), but not glutamine (D51Q) (three amino acids which in proteins have similar properties as aspartate; Glu > Asn > Gln) could partly restore in vitro CAp24 assembly but not the infectivity of the virus particles.

Whereas generally the total protein contents produced by transfected 293T and COS7 cells were reduced as compared to HeLa-tat or HeLa-tat III cells, similar Pr55Gag- processing patterns was repeatedly observed in all mutant and wild type proviral DNA transfected cells. However, intracellular concentrations of CAp24 protein in any of the cells transfected with D51N and D51Q were generally reduced. This could not be explained by the lack of recognition by the antibody used for immunoblotting, since detection with mouse anti-CAp24, rabbit anti-CAp24 or a pool of sera from HIV-infected patients gave similar results. Additionally, analysis with CAp24-ELISA using a different rabbit anti-CAp24-specific antibody also gave similar results. TEM analysis revealed that all mutants were assembly competent but produced virus particles with aberrant core morphology. The virus particles were also able to incorporate HIV-1 glycoprotein but the infectivity of the virus particles was severely reduced or absent suggesting that there was no defect at binding or internalization of these mutants although this was not specifically tested for. Whereas no infectivity was observed with the D51N and D51Q virions, a subtle amount was seen with the D51E viruses in a single cell cycle infectivity assay.

Further analysis of cytoplasmic versus cell membrane CAp24 distribution was also performed with indirect immunofluorescence staining using mouse anti-CAp24 antibody. This analysis revealed a strong staining pattern near or at the plasma membrane (PM) of cells transfected with the three mutants, indicating that there was no defect in intracellular transport of the Pr55Gag precursor to its steady-state destination [13] where activation of the viral protease takes place $[14,15]$. However, all mutants displayed a decreased cytoplasmic staining as compared to the wild type CAp24 control, which showed a diffuse cytoplasmic staining of non-membrane bound Pr55Gag/ CAp24. Perhaps mutated Pr55Gag trafficking and/or assembly is slowed down, or even blocked close to or at the PM in agreement with low levels of mutant particles released. It is also possible that the virus release may have been blocked as a result of inability to form the stabilizing $\beta$-hairpin structure in the N-terminal domain of CAp24 upon proteolytic maturation which is necessary for assembly and release of virions [6].

Self-associative properties of many viral CAp24 proteins have been previously reported [16-19]. However, depending on the protein concentration, salt, and the buffering $\mathrm{pH}[9,20,21]$, the morphology of the assembled structures or the rate of assembly may be variable. The effects of D51 mutations on in vitro CAp24 assembly was monitored spectrophotometrically, and as expected, the assembly rate of both $\mathrm{D} 51 \mathrm{~N}$ and D51E mutants were substantially reduced relative to the wild type protein, although the ability of these mutants to form tubular structures was shown by thin-section transmission electron microscopy (TEM). Thus, it seems likely that the D51N and D51E mutations impose less structural changes than the D51A 
mutation described earlier [6]. Remarkably, although no tubular structure was observed with the D51Q mutant by TEM analysis, an increased optical density measurement that reflects the assembly kinetics was repeatedly observed. We cannot explain this, but, it is possible that the increased OD may result as a consequence of amorphous aggregates that are resistant for stable higher-order CAp24 tube formation.

In a recent study that was published after the present work was performed, Leschonsky et al [22] described the two single amino acid substitution mutations, a D183E and D183N, in an infectious provirus clone HX10. In contrast to our results, they found no effect on extracellular level of the CAp24 protein produced from H1299 cells transfected with the D183E mutant. Additionally, they found no effect on the intracellular level of the CAp24 protein in H1299 cells transfected with the D51N mutant. This may have been owing to the different cell type used. However, we analyzed the viral protein expression profiles in four different cell lines and found similar results.

Lastly, in order to correlate the lack of infectivity with morphological appearances of the viruses, electron microscopy analysis was performed. Only the D51E mutant particles were partially able to form immature- and maturelike viruses that resembled the wild type morphology. Importantly, despite the ability to form wild type-like viruses, the infectivity of D51E virions was significantly reduced, indicating the importance of optimal HIV-1 core stability [23]. With the two other non-infectious mutants, particles with aberrant core structures, either hollowshaped spherical structures in endosomal vesicles (D51N) or particles with distorted core morphology (D51Q) were seen.

Taken together, our data and the other previously published observations $[6,22,24]$ suggest that the invariable D51 residue of HIV is crucial for formation of the $\beta$-hairpin structure in matured CAp24 protein. Additionally, even substitution of D51 with such a similar residue as with glutamate could not restore the integrity of this structure. Furthermore, although our results demonstrated that the D51N and D51E substitutions could restore the in vitro tubular formation, the infectivity of all D51 mutation were rendered non-infectious indicating that this residue is indispensable.

\section{Methods \\ Cells and reagents}

HeLa-tat, 293T, COS7, and TZM-bl cell lines were maintained in Dulbecco modified Eagle medium (DMEM) supplemented with $10 \%$ fetal bovine serum (FBS), penicillin and streptomycin sulphate (Sigma, St Louis MO). H9, Jurkat-tat and MT4 cells were maintained in RPMI
1640 medium (Gibco, Grand Island, NY) supplemented with $10 \%$ fetal bovine serum (FBS; GIBCO), penicillin $(100 \mathrm{U} / \mathrm{ml})$, and streptomycin $(100 \mu \mathrm{g} / \mathrm{ml})$. DEAE-dextran was purchased from Sigma, rabbit polyclonal antibodies against calnexin from Santa Cruz Biotechnology (catalogue no. sc-11397). The following reagents were obtained through the AIDS Research and Reference Reagent Program, Division of AIDS, NIAID, NIH: All adherent cell lines, the protease inhibitor indinavir sulphate (catalogue no. 8145) and TZM-bl cells (catalogue no. 8129) contributed by Dr. John C Kappes [10].

\section{Plasmid DNA construction}

The polymerase chain reaction (PCR) was utilized to develop all plasmids in the study and all constructs were derivatives of the HIV-1 molecular clone pNL4-3 [25]. The HIV-1 CA coding sequence was amplified using PCR and cloned into the prokaryotic expression vector pET11a (Novagen Inc.) essentially as described elsewhere [21,26]. Briefly, the primer pair 5'-ATG GAT CCA TAT GCC TAT AGT GCA GAA CCT CC-3' and 5'-ATG GAT CCT ATC ACA AAA CTC TTG CTT TAT GGC C-3' containing the BamHI/ $\mathrm{NdeI}$ and BamHI, respectively, were used for amplification of the CA sequence (Bam HI/NdeI and BamHI sites are shown in bold). In addition, a translational start codon at the $5^{\prime}$ end (ATG) and two stop codons (TGA/TAG) at the 3 ' end of the sequence were added. The PCR product was subcloned into the TA cloning vector (Invitrogen), transformed in DH5 $\alpha$ E. coli (Escherichia coli), purified and confirmed by sequencing (Cybergene, Sweden). The vector was then digested with NdeI and BamHI and the DNA fragment encoding $C A$ gene was isolated, purified and cloned directionally into the pET11a vector, digested with the same restriction enzymes. Standard procedures were used for restriction digestion. The resulting plasmid was designated pET11a-CA and verified by sequencing.

The three HIV-1 CAp24 mutants, D51N, D51E, and $\mathrm{D} 51 \mathrm{Q}$, in the $\mathrm{PET} 11 \mathrm{a}-\mathrm{CA}$ vector were then engineered by site-directed mutagenesis using the Stratagene's QuickChange $^{\mathrm{TM}}$ Site Directed Mutagenesis Kit (Stratagene) as recommended by the manufacturer. The primer pair used for creating the mutations is listed in Table 1.

The same mutations were also introduced into the HIV-1 molecular clone pNL4-3 $\Delta$ env using the same mutagenic primers described above. QuickChange II XL site-directed mutagenesis kit (Stratagene) was used to create the point mutations in the CA sequence. All plasmid DNAs were then propagated in E. coli XL10-Gold and purified by Maxiprep Purification kit (Qiagen). The identity of each mutation was confirmed by sequencing and the resulting plasmids were digested with BssHII and ApaI. The 1295 bp BssHII/ApaI DNA fragments of the mutated CA sequences were then isolated, purified and cloned directionally into 
Table I: Primers used to create the D5 IN, D5 IE and D5IQ CAp24 mutants

\begin{tabular}{lll}
\hline & 5' primer & 3' primer \\
\hline \multirow{2}{*}{ D5IE } & GCCACCCCACAAGAGT & CATGGTATTTAACTCTT \\
& TAAATACCATG & GTGGGGTGGC \\
D5IQ & GCCACCCCACAACAAT & CATGGTATTTAATTGTT \\
& TAAATACCATG & GTGGGGTGGC \\
D5IN & GCCACCCCACAAAATT & CATGGTATTTAAATTTT \\
& TAAATACCATG & GTGGGGTGGC
\end{tabular}

the pNL4-3 vector, digested with the same restriction enzymes. The resulting plasmids were propagated in DH5 $\alpha$ competent $E$. coli, purified using Maxiprep purification kit and verified by sequencing.

\section{Capsid protein expression and purification}

Competent E. coli Origami (DE3) cells were transformed with the three mutants or the wild-type pET11a-CA expression plasmid, expressed and purified essentially as described elsewhere [26]. Briefly, a single colony from a freshly streaked plate was initially grown in $50 \mathrm{ml} \mathrm{LB}-$ medium containing $100 \mu \mathrm{l}$ Ampicillin (stock 100 mg/ml) and cultured at $37^{\circ} \mathrm{C}$ shaken at 220 r.p.m. Upon reaching optical cell densities at $600 \mathrm{~nm}\left(\mathrm{OD}_{600}\right) \sim 0.6-1.0$, the cells culture was saved at $4^{\circ} \mathrm{C}$ overnight. The following day, $10 \mathrm{ml}$ of culture was added to 1 litre of LB-medium containing ampicillin and incubated with shaking at $37^{\circ} \mathrm{C}$ until the $\mathrm{OD}_{600}$ was $\sim 0.7-1.0$. Protein expression was then induced by addition of isopropylthio- $\beta$-D-galactoside (IPTG) to a final concentration of $1 \mathrm{mM}$. After a 4 hrs incubation period at $37^{\circ} \mathrm{C}$, the cells were harvested by centrifugation at 4000 r.p.m. for $10 \mathrm{~min}$ (Megafuge $2.0 \mathrm{R}$, rotor \#8155, Kendro). The cell pellet was resuspended in $6 \mathrm{M}$ Guanidine-HCl ( $\mathrm{pH}$ 6.5) and stirred for $3 \mathrm{hrs}$ at room temperature before being centrifuged at 10000 r.p.m. for $10 \mathrm{~min}$ at $4^{\circ} \mathrm{C}$ (Beckman Avanti J30-I, rotor 25.50, Beckman Coulter). Fifty $\mathrm{ml}$ of nuclease-free water was slowly added to the supernatant giving a final concentration of 1 $\mathrm{M}$ Guanidine- $\mathrm{HCl}$ to the protein solution. The protein solutions were put in four $15 \mathrm{~cm}$ long dialysis tubings (Spectrpor, MWCO 6-8000, $1.7 \mathrm{ml} / \mathrm{cm}$ ) and dialyzed against $50 \mathrm{mM}$ Tris $\mathrm{pH} 8.0$ overnight at room temperature. Next, the contents of the dialysis tubings were pooled and centrifuged at 10000 r.p.m. for $10 \mathrm{~min}$ at $4^{\circ} \mathrm{C}$ (Beckman Avanti J30-I, rotor 25.50, Beckman Coulter) to remove precipitated proteins. The CAp24 proteins were then precipitated by addition of saturated $\left(\mathrm{NH}_{4}\right)_{2} \mathrm{SO}_{4}$ to a final concentration of $30 \%$ and incubated on ice for $1 \mathrm{~h}$. The CAp24 proteins were then collected by centrifugation at 20000 r.p.m. for $20 \mathrm{~min}$ at $4^{\circ} \mathrm{C}$ (Beckman Avanti J30-I, rotor 25.50, Beckman Coulter). Finally, the protein precipitate was dissolved in a buffer containing $50 \mathrm{mM}$ Tris$\mathrm{HCl} \mathrm{pH}$ 8, $30 \mathrm{mM} \mathrm{NaCl}$ and $1 \mathrm{mM}$ EDTA, and purified on ÄKTA FPLC chromatography system (Amersham Biose- cience). The protein samples were initially loaded onto an anion-exchange column, HiTrap DEAE $1 \mathrm{ml} \mathrm{FF}$, with a mobile phase of $50 \mathrm{mM}$ Tris $\mathrm{pH} 8.0,30 \mathrm{mM} \mathrm{NaCl}$, and 1 $\mathrm{mM}$ EDTA and flow rate of $1 \mathrm{ml} / \mathrm{min}$. The absorbance was measured at $280 \mathrm{~nm}$. The peak fractions containing the CAp24 proteins were pooled and precipitated with 50\% saturated $\left(\mathrm{NH}_{4}\right)_{2} \mathrm{SO}_{4}$ on ice for $1 \mathrm{~h}$. The solution was then centrifuged at 20000 r.p.m. for $20 \mathrm{~min}$ at $4^{\circ} \mathrm{C}$ (Beckman Avanti J30-I, rotor 25.50, Beckman Coulter) and the precipitate was resupsended in $50 \mathrm{mM}$ Tris pH8.0, $30 \mathrm{mM}$ $\mathrm{NaCl}$, and $1 \mathrm{mM}$ EDTA. The purity and integrity of each CAp24 protein was finally analyzed by SDS-PAGE. In order to increase the purity of the CAp24 protein, the samples were loaded onto a gel filtration column, HiLoad 16/ 60 Superdex 75 prep grade, and run with the same mobile phase and as above but with a flow rate of $1.5 \mathrm{ml} / \mathrm{min}$. The peak fractions containing the CAp24 proteins were pooled and concentrated by Amicon Ultra Centrifugal filters (Millipore; MWCO $5 \mathrm{k}$ ) and saved in aliquots at $80^{\circ} \mathrm{C}$. A small aliquot $(10 \mu \mathrm{l})$ was run on SDS-PAGE gel and the protein concentration was determined with a BioRad DC Protein Assay Kit.

\section{Transfection procedure}

Transfection was performed in a 6 -well culture plate using the non-liposomal FuGENE 6 transfection reagent (Roche). Approximately $1 \times 10^{5}$ adherent cells (HeLa-tat, 293T, and COS7) were seeded one day before and transfected with $2 \mu \mathrm{g}$ of each plasmid DNA mixed with $6 \mu \mathrm{l}$ FuGENE 6 transfection reagent. Forty-eight to seventy-two hrs post-transfection, cells were washed in cold PBS and harvested in $1 \times$ RIPA buffer [50 mM Tris ( $\mathrm{pH} 7.4), 150$ $\mathrm{mM} \mathrm{NaCl}, 1 \%$ Triton X-100, 1\% Na-deoxycholate, and $0.1 \%$ SDS] supplemented with a complete protease inhibitor cocktail obtained from Roche.

\section{Virus stock preparation}

Wild type and mutant virus stocks were prepared essentially as described before [27]. Briefly, HeLa-tat, COS7, and $293 \mathrm{~T}$ cells were transfected as described above and three days post-transfection, culture supernatants were clarified from cell debris by centrifugation at 1200 r.p.m. for $7 \mathrm{~min}$, and filtered through $0.45 \mu \mathrm{m}$ filters. Cleared culture supernatants were then treated or not with DNase I (Roche Applied Science) at $20 \mu \mathrm{g} / \mathrm{ml}$ final concentrations at $37^{\circ} \mathrm{C}$ for $1 \mathrm{~h}$ and saved at $-80^{\circ} \mathrm{C}$ until needed. The CAp24 antigen contents of each culture supernatant was determined by an in-house HIV-1 CAp24 antigen ELISA as previously described $[27,28]$.

\section{Virus precipitation}

HeLa-tat, COS7, and 293T cells were transfected with the wild type and mutant proviral DNAs as described above. Approximately seventy-two hrs post-transfection, virionassociated viral proteins were prepared from cell culture 
supernatants by removal of cellular debris by centrifugation at 1200 r.p.m. for $7 \mathrm{~min}$ and filtering through a 0.45$\mu \mathrm{m}$-pore-size membrane. The virus particles in the culture supernatants were then concentrated by centrifugation using Viraffinity (CPC Inc.) essentially as described before [29]. Briefly, clarified culture supernatants were mixed with Viraffinity (3:1) and the mixture was incubated at room temperature for $5 \mathrm{~min}$. They were then centrifuged at $1000 \times \mathrm{g}$ for $10 \mathrm{~min}$ and viral pellets washed twice in a buffer containing $60 \mathrm{mM}$ HEPES, $150 \mathrm{mM} \mathrm{NaCl}$, pH 6.5 . Finally, the viral pellets were dissolved in $1 \times$ RIPA buffer, mixed with $2 \times$ SDS sample buffer and boiled for $5 \mathrm{~min}$ before being subjected to sodium dodecyl sulphate-polyacrylamide gel electrophoresis (SDS-PAGE).

\section{Western blot}

Denatured whole cell extracts or viral lysates were separated on 10-20\% SDS-PAGE gels (Invitrogen), transferred onto a nitrocellulose membrane (Amersham Bioscience) overnight at $4{ }^{\circ} \mathrm{C}$ and detected either with monoclonal anti-CAp24 antibody (kindly provided by Dr Hinkula J), polyclonal anti-CAp24, anti-cyclophilin A, anti-calnexin (Santa Cruz) antibodies or a cocktail of three different HIV-1 positive human sera. As a secondary antibody, appropriate horseradish peroxidase-conjugated antimouse (DAKO; 1:4000), anti-rabbit (Sigma; 1:40000), or anti-human (Pierce; 1:20 000) IgG antibody was used.

\section{Viral infectivity assay}

The mutant and wild type HIV-1 virus stocks were prepared as described above and 100 ng CAp24 antigen equivalents were used to infect MT4 cells. Briefly, $1 \times 10^{5}$ cells were infected with normalized amounts of virus for $3 \mathrm{hrs}$ at $37^{\circ} \mathrm{C}$. The cells were then pelleted, residual virus was removed, and the cell cultures were incubated in fresh complete medium supplemented with FBS and antibiotics at $37^{\circ} \mathrm{C}$ in $5 \% \mathrm{CO}_{2}$. Three days post-infection, the CAp24 antigen contents in the culture supernatants were then processed for CAp24-ELISA.

\section{Single cell cycle infectivity assay}

TZM-bl cells $\left(6 \times 10^{4}\right.$ cells per 12 -well plate) [10] were seeded one day before infection. Following day, medium was removed and cells were infected with mutant and wild type NL4-3 virus. The cells were infected with a virus stock corresponding to $50 \mathrm{ng}$ CAp24 antigen per well with $20 \mu \mathrm{g} / \mathrm{ml}$ DEAE-dextran in a total volume of $300 \mu \mathrm{l}$. After adsorption period of $3 \mathrm{hrs}$, input virus was removed and cells were fed with a complete DMEM containing $10 \mu \mathrm{M}$ indinavir and cultured for 24 hrs. Finally, culture supernatants were removed and cells were lysed with $200 \mu \mathrm{l}$ Glo lysis buffer (Promega). One-hundred $\mu \mathrm{l}$ of the cell lysates were then assayed for luciferase activity using the luciferase assay kit obtained from Promega as recommended by the manufacturer. Measurement of the luminescence was done using the Luminoskan Ascent luminometer (ThermoLabsystem).

\section{In vitro HIV-I CA assembly (Turbidity assay)}

Turbidity assay is a valuable technique used to study a salt-induced self-assembly process of CAp24 by monitoring polymerization of CAp24 spectrophotometrically, as the rate of CAp24 tube formation increases sample turbidity $[9,30,31]$. The assay was performed at room temperature using a BioSpec-1601E spectrometer (Shimadzu) and the absorbance was set to $350 \mathrm{~nm}$ wavelength. One-hundred $\mu \mathrm{M}$ of highly purified HIV-1 CAp24 protein of each mutant and the wild type control was mixed with $50 \mathrm{mM}$ $\mathrm{NaH}_{2} \mathrm{PO}_{4}$ (pH 8.0). Tubular CAp24 assembly was then induced by addition of $2.0 \mathrm{M} \mathrm{NaCl}$ solution, and the assembly rates was monitored by a spectrophotometer as the rate of tube formation increases the sample turbidity. Absorbance measurements were made every $10 \mathrm{~s}$ for up to $60 \mathrm{~min}$. The assembly rate was then set by plotting the absorbance versus time.

For TEM analysis, $100 \mu \mathrm{M}$ of each mutant and the wild type CAp24 protein was mixed with $50 \mathrm{mM} \mathrm{NaH} \mathrm{PO}_{4}$ (pH 8.0) and $1.0 \mathrm{M} \mathrm{NaCl}$ solution. The mixture was then immediately transferred to a $37^{\circ} \mathrm{C}$ and incubated for $1 \mathrm{~h}$. Finally, the samples were fixed with freshly made $2.5 \%$ formaldehyde and processed for TEM analysis.

\section{Immunofluorescence assay}

HeLa-tat III cells $\left(1.5 \times 10^{3}\right.$ cells per well in 4 -well chambered slides from Nunc) were cultured one day before and transfected with $2 \mu \mathrm{g}$ of mutant and wild type proviral DNA constructs. Forty-eight hrs post-transfection, cells were fixed in aceton/methanol (1:1) for $5 \mathrm{~min}$ and washed with PBS. Slides were then incubated with primary anti-CAp24 monoclonal antibody and 4',6-diamidino-2-phenylindole dihydrochloride (DAPI) at $37^{\circ} \mathrm{C}$ for 1 h. DAPI was used to labell the cellular DNAs. Cells were washed three times in PBS and further incubated with secondary antibody for $1 \mathrm{~h}$. FITC-conjugated rabbit antimouse IgG antibody (DAKO) was used as secondary antibody. After the final wash, slides were mounted and flourescent images were aquired by using a Nikon Eclipse E600 phase-contrast fluorescent microsope.

\section{Transmission electron microscopy analysis}

Cells were prepared for electron microscopy essentially as described elsewhere [32]. Briefly, transfected HeLa-tat cells and virus infected Jurkat-tat cells (data not shown) were fixed by freshly made $2.5 \%$ glutaraldehyde in phosphate buffer and post-fixed in $1 \% \mathrm{OsO}_{4}$. The cells were embedded in epon and post-stained with $1 \%$ uranyl acetate. Epon sections were cut at approximately $60 \mathrm{~nm}$ thick to accommodate the volume of the core structure parallel 
to the section plane. Duplicate sample preparations were done, which were then analyzed by electron microscope.

Additionally, in vitro assembled CAp24 proteins were negatively stained with $2 \%$ ammonium molybdate at $\mathrm{pH}$ 8.0 to study the CAp2 4 tubular formation.

\section{Competing interests}

The author(s) declare that they have no competing interests.

\section{Authors' contributions}

SA and MY contributed equally to the experimental work. $\mathrm{SA}$ wrote the manuscript with $\mathrm{AV}$. AV is the principal investigator. SH performed all electron microscopy analysis. All authors read and approved the manuscript.

\section{Acknowledgements}

We thank Alireza Padjand for help with the cloning and initial characterization of the prokaryotic expression plasmids. This work was supported by grants from the Swedish Medical Research Council (grant no. K2000-06X0950 I- IOB), Swedish International development Cooperation Agency, SIDA (grant no. 2006-00I I786) and Tripep AB.

\section{References}

I. Wiegers K, Rutter G, Kottler H, Tessmer U, Hohenberg H, Krausslich HG: Sequential steps in human immunodeficiency virus particle maturation revealed by alterations of individual $\mathbf{G a g}$ polyprotein cleavage sites. J Virol 1998, 72:2846-2854.

2. Morikawa Y, Shibuya M, Goto T, Sano K: In vitro processing of human immunodeficiency virus type I Gag virus-like particles. Virology 2000, 272:366-374.

3. Briggs JA, Simon MN, Gross I, Krausslich HG, Fuller SD, Vogt VM, Johnson MC: The stoichiometry of Gag protein in HIV-I. Nat Struct Mol Biol 2004, I I (7):672-675.

4. Monaco-Malbet S, Berthet-Colominas C, Novelli A, Battai N, Piga N, Cheynet V, Mallet F, Cusack S: Mutual conformational adaptations in antigen and antibody upon complex formation between an Fab and HIV-I capsid protein p24. Structure 2000, 8(1 0): 1069-1077.

5. Li S, Hill CP, Sundquist WI, Finch JT: Image reconstructions of helical assemblies of the HIV-I CA protein. Nature 2000, 407(6802):409-4I3.

6. von Schwedler UK, Stemmler TL, Klishko VY, Li S, Albertine KH, Davis DR, Sundquist WI: Proteolytic refolding of the HIV-I capsid protein amino-terminus facilitates viral core assembly. Embo J 1998, I7(6): I555-1568.

7. Tang C, Ndassa Y, Summers MF: Structure of the N-terminal 283-residue fragment of the immature HIV-I Gag polyprotein. Nat Struct Biol 2002, 9(7):537-543.

8. Mortuza GB, Haire LF, Stevens A, Smerdon SJ, Stoye JP, Taylor IA: High-resolution structure of a retroviral capsid hexameric amino-terminal domain. Nature 2004, 43 I(7007):48I-485.

9. Lanman J, Sexton J, Sakalian M, Prevelige PE Jr.: Kinetic analysis of the role of intersubunit interactions in human immunodeficiency virus type I capsid protein assembly in vitro. J Virol 2002, 76( I 4):6900-6908.

10. Wei X, Decker JM, Liu H, Zhang Z, Arani RB, Kilby JM, Saag MS, Wu $X$, Shaw GM, Kappes JC: Emergence of resistant human immunodeficiency virus type $I$ in patients receiving fusion inhibitor (T-20) monotherapy. Antimicrob Agents Chemother 2002, 46(6): 1896-1905.

I I. Coffin JM: Genetic diversity and evolution of retroviruses. Curr Top Microbiol Immunol 1992, I 76: | 43-164.

12. Bouamr F, Cornilescu CC, Goff SP, Tjandra N, Carter CA: Structural and dynamics studies of the D54A mutant of human $T$ cell leukemia virus-I capsid protein. J Biol Chem 2005, 280(8):6792-680I.
13. Finzi A, Orthwein A, Mercier J, Cohen EA: Productive Human Immunodeficiency Virus Type I Assembly Takes Place at the Plasma Membrane. 2007, 8 I (I 4):7476-7490.

14. Kaplan AH, Manchester M, Swanstrom R: The activity of the protease of human immunodeficiency virus type $I$ is initiated at the membrane of infected cells before the release of viral proteins and is required for release to occur with maximum efficiency. J Virol 1994, 68(1 0):6782-6786.

15. Vogt VM: Proteolytic processing and particle maturation. Curr Top Microbiol Immunol 1996, 2 I 4:95-I3I.

16. Burnette WN, Holladay LA, Mitchell WM: Physical and chemical properties of Moloney murine leukemia virus $\mathrm{p} 30$ protein: a major core structural component exhibiting high helicity and self-association. J Mol Biol 1976, I07(2): I3 I-I 43 .

17. Ehrlich LS, Krausslich HG, Wimmer E, Carter CA: Expression in Escherichia coli and purification of human immunodeficiency virus type I capsid protein (p24). AIDS Res Hum Retroviruses 1990, 6(10): I I69-II75.

18. Pinter A, Fleissner E: Structural studies of retroviruses: characterization of oligomeric complexes of murine and feline leukemia virus envelope and core components formed upon cross-linking. J Virol 1979, 30(I): I57-I65.

19. Pepinsky RB, Cappiello D, Wilkowski C, Vogt VM: Chemical crosslinking of proteins in avian sarcoma and leukemia viruses. Virology 1980, I02(I):205-210.

20. Ehrlich LS, Liu T, Scarlata S, Chu B, Carter CA: HIV-I capsid protein forms spherical (immature-like) and tubular (maturelike) particles in vitro: structure switching by $\mathrm{pH}$-induced conformational changes. Biophys J 200I, 8 I (I):586-594.

21. Gross I, Hohenberg H, Krausslich HG: In vitro assembly properties of purified bacterially expressed capsid proteins of human immunodeficiency virus. Eur J Biochem 1997, 249(2):592-600.

22. Leschonsky B, Ludwig C, Bieler K, Wagner R: Capsid stability and replication of human immunodeficiency virus type I are influenced critically by charge and size of $\mathbf{G a g}$ residue 183 . 2007, 88(I):207-216.

23. Forshey BM, von Schwedler U, Sundquist WI, Aiken C: Formation of a human immunodeficiency virus type I core of optimal stability is crucial for viral replication. J Virol 2002, 76( I I):5667-5677.

24. Tang S, Murakami T, Agresta BE, Campbell S, Freed EO, Levin JG: Human immunodeficiency virus type I $\mathbf{N}$-terminal capsid mutants that exhibit aberrant core morphology and are blocked in initiation of reverse transcription in infected cells. J Virol 200I, 75(19):9357-9366.

25. Adachi A, Gendelman HE, Koenig S, Folks T, Willey R, Rabson A, Martin MA: Production of acquired immunodeficiency syndromeassociated retrovirus in human and nonhuman cells transfected with an infectious molecular clone. J Virol 1986, 59(2):284-29l.

26. Ehrlich LS, Agresta BE, Carter CA: Assembly of recombinant human immunodeficiency virus type I capsid protein in vitro. J Virol 1992, 66(8):4874-4883.

27. Abdurahman S, Hoglund S, Hoglund A, Vahlne A: Mutation in the loop C-terminal to the cyclophilin A binding site of HIV-I capsid protein disrupts proper virus assembly and infectivity. Retrovirology 2007, 4(I): 19.

28. Horal P, Svennerholm B, Jeansson S, Rymo L, Hall WW, Vahlne A: Continuous epitopes of the human immunodeficiency virus type I (HIV-I) transmembrane glycoprotein and reactivity of human sera to synthetic peptides representing various HIV-I isolates. J Virol I991, 65(5):2718-2723.

29. Abdurahman S, Hoglund S, Goobar-Larsson L, Vahlne A: Selected amino acid substitutions in the $C$-terminal region of human immunodeficiency virus type I capsid protein affect virus assembly and release. J Gen Virol 2004, 85(Pt I0):2903-29I3.

30. Douglas CC, Thomas D, Lanman J, Prevelige PE Jr.: Investigation of $\mathrm{N}$-terminal domain charged residues on the assembly and stability of HIV-I CA. Biochemistry 2004, 43(32): I 0435-I044I.

31. Tang C, Loeliger E, Kinde I, Kyere S, Mayo K, Barklis E, Sun Y, Huang M, Summers MF: Antiviral inhibition of the HIV-I capsid protein. J Mol Biol 2003, 327(5): I013-1020.

32. Hoglund S, Su J, Reneby SS, Vegvari A, Hjerten S, Sintorn IM, Foster $H$, Wu YP, Nystrom I, Vahlne A: Tripeptide interference with 
human immunodeficiency virus type I morphogenesis. Antimicrob Agents Chemother 2002, 46(I I):3597-3605.

33. Massiah MA, Starich MR, Paschall C, Summers MF, Christensen AM, Sundquist WI: Three-dimensional Structure of the Human Immunodeficiency Virus Type I Matrix Protein. Journal of Molecular Biology 1994, 244(2): 198-223.

34. Gamble TR, Vajdos FF, Yoo S, Worthylake DK, Houseweart M, Sundquist WI, Hill CP: Crystal structure of human cyclophilin A bound to the amino-terminal domain of HIV-I capsid. Cell 1996, 87(7): | 285-1294.

35. DeLano WL: The PyMOL Molecular Graphics System. 2002.

Publish with Biomed Central and every scientist can read your work free of charge

"BioMed Central will be the most significant development for disseminating the results of biomedical research in our lifetime. "

Sir Paul Nurse, Cancer Research UK

Your research papers will be:

- available free of charge to the entire biomedical community

- peer reviewed and published immediately upon acceptance

- cited in PubMed and archived on PubMed Central

- yours - you keep the copyright

Submit your manuscript here:

http://www.biomedcentral.com/info/publishing_adv.asp
BioMedcentral 